\title{
Pertussis: Incidence and Surveillance in Municipalities of 6 Regional Health Management of Paraíba, Brazil
}

Juliane Oliveira Costa Nobre ${ }^{1}$, Elicarlos Marques Nunes², Ana Lúcia Frugis $\mathrm{Yu}^{3}$, Milena Nunes Alves de Sousa ${ }^{4}$, Theonys Diógenes de Freitas ${ }^{5}$, Raquel Campos de Medeiros ${ }^{6}$ Manuela Carla de Souza Lima Daltro7, Adyl Carlos Ferreira Rodrigues ${ }^{8}$, Denisy Dantas Melquíades Azevedo9, Silvia Ximenes Oliveira ${ }^{10}$, Fabriciano Santos Souza ${ }^{11}$, Isabella Evelle Sales Lima ${ }^{11}$, José Cássio de Moraes ${ }^{12}$

\section{Abstract}

Introduction: Pertussis is an infectious and highly contagious disease of the respiratory tract, caused by a bacterium called Bordetellapertussis. It can occur at any stage of life. The prevention of whooping cough is effective part of the National Immunization Program (NIP) in Brazil, which offers the vaccine free of in public health. Data relative to notifications of cases of whooping cough in Brazil are stored and grouped in the Notifiable Diseases Information System (SINAN).

Objective: This study aimed to know the incidence and surveillance for pertussis in municipalities linked the $6^{\text {th }}$ Regional Health Management of Paraiba, and as specific, assess the completeness of data of reported cases and verify the use of antibiotics in all reported cases of disease.

Method: It is a study of epidemiological type of analytical and descriptive character.

Results: The results show that most cases occurred in 2013, a fact overlooked by the Regional which showed no action to contain the disease occurrence. What in epidemiological terms directly affects any action that might promote rapid response on measures to enable new cases.
1 Nurse. Master in Health Sciences. Teacher in the Department of Nursing*.

2 Nurse. Master in Public Health. Teacher in the Department of Nursing*.

3 Doctor. PHD from the Faculty of Veterinary Medicine and Zootechny of the University of São Paulo.

4 Nurse. PHD in Health Promotion. Teacher in the Department of Medicine*.

5 Veterinarian. Doctor in Veterinary Medicine. Teacher in the Department of Medicine*.

6 Nurse. PhD in Health Sciences. Teacher in the Department of Nursing*.

7 Physical Therapist. Master in Health Sciences. Teacher in the Department of Physical therapy*

8 Nurse. Specialist in Urgent and Emergency and Intensive Care Unit.

9 Nurse. Specialist in Intensive Care Unit and in Nursing Work. Teacher in the Department of Nursing*.

10 Nurse. Master in Nursing. Teacher in the Department of Nursing*.

11 Nurses Graduates for*.

12 Doctor. PhD in Public Health. Adjunct Teacher, Faculty of Medical Sciences of Santa Casa de São Paulo.

*: Faculdades Integradas de Patos, Paraíba, Brazil.

Contact information:

Elicarlos Marques Nunes.

Address: Rua. Horácio Nóbrega, S/N, Bairro Belo Horizonte, Patos, Paraíba, Brazil. CEP 58.704-000.

Đ elicarlosnunes@yahoo.com.br 
Conclusions: It is important to adopt strategies to identify early the incidence of cases as a way to control or suppress the disease to a small group, so it is necessary to have enough information for diagnosis and treatment.

\section{Keywords}

Pertussis; Epidemiology; Incidence.

\section{Introduction}

Pertussis is an infectious and highly contagious disease of the respiratory tract, caused by a bacterium called Bordetellapertussis. It can occur at any stage of life, but mainly affects children, it is a disease of great importance, in view of its high rate of mortality in children. [1]

This is an endemic and epidemic condition, with outbreaks every 3-5 years. According to the World Health Organization, in 2008, there were 16 million cases (95\% of them in developing countries) and enrolled 195,000 deaths (WHO, 2016). In Brazil, in 2011, 2,258 cases were reported and 55 deaths, and in 2012, 5,124 cases and 86 deaths, mostly in babies under six months old. [2]

The prevention of whooping cough is effective part of the National Immunization Program (NIP) in Brazil, which offers the vaccine free in the public health system. [3] The immunity conferred by the vaccine for pertussis component decreases with time. Several studies worldwide have shown that the protection against pertussis decreases from six to 12 years after vaccination, may be too low or zero. [4]

The pertussis vaccine became part of the national vaccination schedule in 1973, however, from the year 2010, it has been noticed the resurgence of the disease in some Brazilian capitals, and the majority of these cases occurred in children less than three months, because they have not yet received the full course of vaccination (at least three doses of pentavalent) or by even have started this scheme, as recommended by the Ministry of Health. $[5,6]$
Data relative to the notifications of cases of whooping cough in Brazil are stored and grouped in the Notifiable Diseases Information System (SINAN). [7] SINAN was developed in the 90s, with the objective of collecting and processing data on notification of diseases throughout the country, providing information to identify the epidemiological reality of a given area.

Contributing, thus, to the decision-making at the local, state and federal levels. For this notification, standardized chips are available by the Ministry of Health, which contains information necessary for a full investigation of the case, thus enabling a greater understanding of the disease and its epidemiology where it is occurring.

Given the potential of this disease, no cough should go unnoticed by health professionals, which is necessary a more careful approach of the signs and symptoms, as well as make laboratory tests to confirm the disease and determining the etiologic agent.

Among the tests used for diagnosis of disease, isolation of the pathogen through nasopharyngeal aspirate culture is the most accurate, being carried out with suitable technique. Other complementary tests can be used to help diagnose among them: the white cell count, chest X-ray and PCR, the latter being indicated only when the symptoms are a signal indicative of whooping cough. [8]

The treatment and chemoprophylaxis of pertussis is through antibiotics, which must be prescribed only by trained professionals, given their particular choice of medication and appropriate dosage for infants, children, adults and pregnant women. 
The $6^{\text {th }}$ Regional Management of Health in Paraiba state consists of 24 linked municipalities, where it receives enough data to perform a research of analysis of incidence and surveillance of whooping cough. The choice of 6 GRS is because there is no dissemination of the disease data by it and by the difficulty of access to other management.

This study is of great importance for the whole community and health professionals, in order to inform how it presents itself in the region, promote health education in order to decrease the epidemiological indices, and to provide subsidies to trace coping strategies to the disease by managers.

Therefore, this study has as general aim to know the incidence and surveillance for pertussis in municipalities linked the $6^{\text {th }}$ Regional Health Management of Paraiba, and as specific, assess the completeness of data of reported cases and verify the use of antibiotics in all reported cases of the desease.

\section{Methods}

This study is an epidemiological type of analytical and descriptive character, which sought to examine the incidence and surveillance of whooping cough through secondary data, with a quantitative approach.

The survey was conducted in epidemiological surveillance department of the $6^{\text {th }}$ GRS, located in Patos, Paraíba [PB]. It is responsible for coordinating actions of 24 municipalities tied to it. The study population consisted of 38 cases reported to the Notification Diseases Information System -SINAN. As inclusion criteria, was adopted all reported cases residing in the $6^{\text {th }}$ GRS, from 2008 to 2014, and as exclusion criterion, those living outside the local management of study. After applied these criteria, it was amounted a sample of 29 cases. To collect data, we used the database of the $6^{\text {th }}$ GRS and the file of Notifiable Diseases Information System (SINAN).
We collected epidemiological data regarding the purpose of the study, as a city of the occurrence of the disease, antibiotic use, and complete filling of data to characterize the completeness of cases. Data collection occurred from September to October 2014. For the data collection process, the researchers took into account the requirements contained in Resolution 466/12, which regulates research involving human beings, ensuring the security and privacy of involved. [9] For this, we used a Risk Protection and Confidentiality Agreement (TPRC), to be given access to information, examination, observation of personal data and documents. The study was approved by the Research Ethics Committee of Patos Integrated College and the Platform Brazil, under protocol number - CAAE: 310071145.5.0000.5181.

Data analysis was based on study of descriptive epidemiology. For qualitative variables were made the absolute frequencies ( $\mathrm{n}$ ) and relative (\%), shown in tables and/or graphics. We calculated the average incidence of the period from 2008 to 2014, the number of cases divided by 7 and as the denominator the population of the center of the period, 2011, 100,000 times.

\section{Results and Discussion}

In Table 1 it is observed that most of the cases occurred in 2013 with the municipalities of Santa Luzia and Catingueira with higher incidence, a fact overlooked by the Regional which showed no action to contain the disease occurrence. What in epidemiological terms directly affects any action that might promote rapid response as the measures to enable the incidence of new cases.

Studies show that about 50 million cases, with approximately 300,000 deaths occur each year in the world, and its lethality in children can approach $4 \%$, whooping cough is the third leading cause of death among the immunopreventable diseases, what leaves it as an important condition of com- 
Table 1. Average coefficient of suspected cases of whooping cough in the 6th GRS-PB, according to municipality from 2008 to 2014 . The columns for the years represent the total number of cases each year.

\begin{tabular}{|l|c|c|c|c|c|c|c|c|c|c|c|}
\hline \multicolumn{1}{|c|}{ Municipality } & $\mathbf{2 0 0 8}$ & $\mathbf{2 0 0 9}$ & $\mathbf{2 0 1 0}$ & $\mathbf{2 0 1 1}$ & $\mathbf{2 0 1 2}$ & $\mathbf{2 0 1 3}$ & $\mathbf{2 0 1 4}$ & Total & Average & $\begin{array}{c}\text { Population } \\
\mathbf{2 0 1 1}\end{array}$ & Incidence \\
\hline Catingueira & 0 & 0 & 0 & 0 & 0 & 3 & 0 & 3 & 0.42 & 4812 & 8.91 \\
\hline Junco do Seridó & 0 & 0 & 0 & 0 & 0 & 0 & 1 & 1 & 0.14 & 6643 & 2.15 \\
\hline Maturéia & 0 & 0 & 0 & 0 & 0 & 0 & 1 & 1 & 0.14 & 5939 & 2.41 \\
\hline Patos & 2 & 0 & 1 & 0 & 2 & 0 & 5 & 10 & 1.42 & 100674 & 1.42 \\
\hline Santa Luzia & 0 & 0 & 0 & 0 & 0 & 11 & 0 & 11 & 1.57 & 14719 & 10.68 \\
\hline S. Jose de Espinharas & 0 & 0 & 0 & 0 & 0 & 1 & 0 & 1 & 0.14 & 4734 & 3.02 \\
\hline São Mamede & 0 & 0 & 0 & 0 & 1 & 0 & 1 & 2 & 0.28 & 7748 & 3.69 \\
\hline 6a region & 2 & 0 & 1 & 0 & 3 & 15 & 8 & 29 & 4.14 & 145269 & 2.85 \\
\hline
\end{tabular}

Source: Regional Health Center of the 6th Region of the State of Paraiba, 2014. * For 100,000 inhabitants.

pulsory notification, and should be notified immediately. [10]

Because, as we know, that it is a disease of compulsory notification and where your infection rate is still high, the earlier they are carried out actions that enable the recognition, prevention and prophylactic measures, the lower the amount of individuals and subjects who may be infected with the pathogen.

Hence the importance of the $6^{\text {th }}$ Regional Management of Health, to identify these notifications, and then map out a plan of actions in the municipalities where the incidence of cases are relatively high compared with the other, it should also be noted that the look of managers and health professionals do not should only summarize to points where the disease is more frequent, but also in other cities, since there may be a probability of the significant increase in the number of new cases.

The degree of spread of this disease is pretty strong, the point still remains a considerable problem in many countries. In the United States, for example, since the end of the 80s, several epidemics of whooping cough have occurred relatively frequently. [11] Therefore, there is the need to notify and treat immediately suspected or confirmed cases, in order to decrease the radius of infection that this condition can reach in a given space.
According to WHO data, the incidence of pertussis has tripled in Latin America and North America between 2006 and 2008, in 2012, the 1,759 cases in Brazil have caused 39 deaths, most babies, which alert us that precautionary measures against the disease can be taken. [12] (Table 2)

Table 2. Use of antibiotics in suspected cases of Pertussis, 6th GRS of Paraiba 2008-2014.

\begin{tabular}{|l|c|c|}
\hline \multicolumn{1}{r|}{ Antibiotic } & F & $\%$ \\
\hline Yes & 22 & 75.90 \\
\hline No & 4 & 13.80 \\
\hline Unknown & 3 & 10.30 \\
\hline Total & 29 & 100.00 \\
\hline
\end{tabular}

Source: Health Regional Center of the $6^{\text {th }}$ Region of the State of Paraiba, 2014.

According to the table above, it is noted that more than half of the cases made use of antibiotics. Antibiotic therapy is still an effective prophylactic measure, especially in response time that antibiotics may contribute to the improvement of infected individuals, but counterpart the use of these substances prior to the results for serology of pertussis, commits the data and research in regards the confirmation of the disease or not.

For, even before the confirmed result, it is common in hospitals which treat suspected of whooping cough people, medical professionals come with an- 
tibiotic therapy regimen for treatment, so we believe that the data on the number of cases could be higher as compared to the presented here and reported by the Compulsory Notification System.

The Ministry of Health recommends the use of erythromycin as the drug of first choice in the treatment and in chemoprophylaxis of whooping cough and, as a second option, clarithromycin. [13] Erythromycin is the more efficient and less toxic antibiotics. This antibiotic is able to eradicate the agent in the body in 1 or 2 days, when its use is initiated during the catarrhal period or in the early paroxysmal period, thereby promoting the reduction of the period of communicability of the disease. [14]

In the records of SINAN, as well as in the database does not have the variable on which types of antibiotics were used and at what stage the individual has used, since the use of antibiotics prior to collection for laboratory analysis compromises the quality of the material, perhaps it justifies the fact that only one case has been confirmed by laboratory in $6^{\text {th }}$ GRS. (Table 3)

Table 3. Completeness of data of suspected cases in the $6^{\text {th }}$ GRS - PB, 2008-2014.

\begin{tabular}{|l|c|c|c|c|}
\hline \multicolumn{1}{|c|}{ Variables } & \multicolumn{2}{c|}{$\begin{array}{c}\text { Cases with } \\
\text { information }\end{array}$} & \multicolumn{2}{c|}{$\begin{array}{c}\text { Cases without } \\
\text { information }\end{array}$} \\
\cline { 2 - 5 } & N & $\%$ & N & $\%$ \\
\hline Name & 27 & 93 & 2 & 07 \\
\hline Date of birth & 27 & 93 & 2 & 07 \\
\hline Results of culture & 12 & 41 & 17 & 59 \\
\hline Vaccination status & 21 & 72 & 8 & 28 \\
\hline Case evolution & 27 & 93 & 2 & 07 \\
\hline Communicants & 10 & 34 & 19 & 66 \\
\hline Source: Regional Center of Health of the 6 & \multicolumn{3}{c|}{ State of Paraiba, 2014.} \\
\hline
\end{tabular}

Through data completeness, it is found that some important data are no longer reported in the suspected case notification, as: result of culture, vaccination status and communicating. This lack of information does not allow us to know concretely the epidemiological profile of the disease in the region.
It is important, because it is a public body, in particular that stands out in health actions, that the $6^{\text {th }}$ Management recognizes its importance, and search to centralize actions against whooping cough, as well as qualify the professionals in the municipalities in which are part of the same, so that they are able to act as soon as possible in the notification of suspected cases, trying to obey the calling for the Ministry of Health, which says that the nasopharyngeal sample must be performed in the catarrhal stage, before the start of antibiotic therapy or up to 3 days of starting treatment.

But despite the failure in the transfer of information of notified cases, because of poor filling of SINAN records by professionals, the results of this study show that is having an increase in whooping cough in the municipalities of 6 of Paraíba Regional Health Management for the period from 2008 to 2014, this already warn the sign that there needs to be more in-depth study to identify where the deficit of the shares, and can particularly improve the measures that enable a reduction in the number of cases.

The findings of this study highlight the lack of information in the SINAN forms, filled precariously by some professionals, leaving important information not only for this study, but to obtain concrete results on the epidemiological profile of the disease in the region, resulting in lack of preventive measures, spreading the disease and increase in cases.

The Compulsory Notification System is still important valuable source of epidemiological information, despite its limitations. It is necessary to implement actions to improve the quality of information, through the complete filling of all fields of the notification form. [15]

The diagnostic of confirmation is made by bacterial culture, which is the gold standard in the diagnosis, or its isolation by polymerase chain reaction (PCR) in real time in oropharyngeal secretions, preferably harvested in the catarrhal stage of the 
disease, before antibiotics or at most three days of treatment as recommended. [16]

Additional tests can help to confirm or disposal of suspected cases, which is of fundamental importance to have reliable results so that we can treat and combat centrally the disease, respecting the treatment indicators for each step in that the patient is unhealthy. [17]

Leukogram: in the catarrhal period, there may be a relative and absolute lymphocytosis, usually above 10,000 lymphocytes $/ \mathrm{mm}^{3}$. The total leukocytes, at the end of this stage, reach a value generally greater than 20,000 leukocytes $/ \mathrm{mm}^{3}$. In paroxysmal period, the number of leukocytes may amount to up to 30,000 or $40,000 / \mathrm{mm}^{3}$, associated to the lymphocytosis from 60 to $80 \%$.

Chest X-ray: recommended in children under 4 years, to aid in the differential diagnosis and/or the presence of complications. It is characteristic the image of "blurred heart" or "feathering", because the edges of the cardiac imaging are not clear, due to pulmonary infiltrates.

In order to explain these laboratory procedures, are essential that scholars on the subject to abide the following explanations of who deeply experienced the subject under discussion "The easiest and sensitive for the diagnosis is by PCR respiratory secretion, but also culture It should be used, but this can lead to diminished sensitivity if the patient is already in use of antimicrobials or vaccinated patients. Serology only have benefit in vaccinated patients for over 02 years, and should be taken in two phases, the first sample preferably harvested in the catarrhal stage.[8]

The $P C R$, is important to note, diagnoses both dead bacteria as the living. Therefore, it is possible that it may be before the detection of a bacterium that is already dead, but that caused an infection several weeks ago. Therefore, the test should be given only when the symptoms are a signal indicative of pertussis. [8]

The collection of material suspected of pertussis cases should be proceeded preferably at the begin- ning of the peculiar symptoms of the disease (catarrhal period). This fact should be undertaken prior to antibiotic therapy or at most two or three days. Performing the collection, it should be introduced a flexible swab, ultrathin and sterile in the nostril of the patient to find a contact with the posterior wall of the nasopharynx. Subsequently, perform rotational movements. [18]

To be considered its high rate of effectiveness, vaccination matches as a mandatory component in immunization and public health programs. Vaccination is still the best strategy among the tested in preventing this disease, because it causes a greater reduction in the number of cases in all age groups and achieves greater impact among children under one year, the most vulnerable to complications from whooping cough. [19]

The immunization coverage rates for pertussis vaccine increased in recent years in 17 countries. [20] However, this increase was not uniform in Brazil, according to data from Monitoring System of indicators of the Pact's for Health (SisPacto) indicate that this rate decreased from 103.1 to $91.8 \%$. [21]

These aspects can be attributed to sociodemographic factors, in which significantly hinder the adherence to preventive measures for the disease. Family size, low parental education and long distance between the residence of the children to the Family Health Strategies, may be associated with reduction in vaccination coverage. [22]

It is important that have the awareness by the community as a whole and the importance of vaccination and their vaccination schedules for children, it is necessary that health professionals can act in a cohesive way, knowing and meeting the aspirations that the community where he works, because from that knowledge he can adopt measures that can contribute to favorable numbers as vaccination in the prevention of notifiable diseases, including whooping cough.

It is noteworthy that is notoriously evident that most cases of infection with whooping cough are in 
children younger than 1 year of age, the answer to this data to be so high is precisely in the vaccination, and their vaccination schedules, the fact is that due the young age many children are vaccinated later or do not have the vaccine scheme closed to the disease which leaves them more suggestible.

The immunity conferred by pertussis component does not last for the entire life of the individual, and it decreases with time. On average, 5 to 10 years after the last dose of vaccine, the protection may be scarce or absent. [1]

\section{Conclusions}

Despite the difficulty in obtaining some epidemiological data on pertussis and the lack of updated data on epidemiology in the municipalities that are managed by the $6^{\text {th }}$ Regional Health of Paraiba, we could identify that pertussis is still a serious health problem, as some factors can further contribute to this disease each day more aggressive. Since the disease is an important cause of morbidity and mortality, especially in children under one year of age, which requires increased attention of government agencies in health in the adoption of measures to enable the prevention and identification of the disease, thus preventing new cases arise.

Therefore, it is important to adopt strategies to identify early the incidence of cases, as a way to control or suppress the disease to a small group, so it is necessary to have enough information for diagnosis and treatment, fact that, in our study, we observed that some information and parameters regarding the diagnosis and notification of the disease, were not followed or did not figure in the notification form, a fact that contributes to the deficit of positive results, in which enable us to know epidemiology of the disease and surveillance tools.

The study allows new shares to be adopted by the $6^{\text {th }} \mathrm{GRS}$ as a way to review our work against the disease in focus for the coming years and maintain high vaccination coverage, as well as having benefits for a new approach to awareness means and guidance of the population to combat whooping cough.

\section{References}

1. Brazil. Ministry of Health. Secretariat of Health Surveillance. Epidemiological Surveillance Guide. 7th ed. Brasilia DF); Ministry of Health; 2009. 816 p. Available at: <http://bvsms.saude.gov. br/bvs/publicacoes/guia vigilancia epidemiologica 7ed.pdf> Accessed on: July 28, 2016.

2. Bricks LF. Pertussis: new vaccination strategies for preventing an ancient disease. J Health BiolSci. 2013; 1 (2): 73-83

3. Ministry Of Health (BR). Department of Information Health of the System for Health Pact:. Available in: http://www2.datasus. gov.br/DATASUS/index.php?area $=0201$

4. Brazil. Ministry of Health. SINAN. National System of Notifiable Diseases. Brasília (DF), 2014b. Available at: http:// renastonline.ensp.fiocruz.br/temas/sistema-nacional-agravosnotifica\%C3\%A7\%C3\%A3o-sinan Accessed on: July 26, 2016.

5. Brazil. Ministry of Health. Department of Epidemiological Surveillance. technical report for the implementation of the absorbed diphtheria, tetanus and pertussis (acellular pertussis) adult type - Tdap. Brasília (DF), 2014th.

6. Torres RS. Resurgence of pertussis at the age of vaccination: clinical, epidemiological, and molecular aspects. J Pediatr (Rio J). 2015; 91: 333-8

7. Brasil. Ministério da Saúde. Secretaria de Vigilância em Saúde. Guia de vigilância epidemiológica/Ministério da Saúde, Secretaria de Vigilância em Saúde. $6^{\circ}$ ed. Brasília: Ministério da Saúde, 2005, $816 p$.

8. Motta F, Cunha J. Pertussis: Current revision of an old disease. BolCient Ped. 2012; 1 (2): 43

9. Brazil. Ministry of Health. National Health Council. National Committee for Ethics in Research - CONEP. Resolution No. 466/2012 on research involving humans. Brasilia, 2012.

10. World Health Organization. Immunization, Vaccines and Biologicals. Pertussis. Geneva: World Health Organization, 2013. Available at: http://www.who.int/immunization/topics/ pertussis/en/ Accessed on: July 26, 2016

11. Araújo M. Coqueluche. Curso de Enfermagem na ISES. 2009. Disponível em: http://www.ebah.com.br/content/ ABAAAAYMsAl/coqueluche. Acesso em: 14 jul. 2014.

12. Brasil, AÇÕES Desenvolvidas contra a Epidemiologia da Coqueluche no Brasil. 2014.: Disponível em: http:// portalsaude.saude.gov.br/index.php/o-ministerio/principal/ leia-mais-o-ministerio/636-secretaria-svs/vigilancia-de-a-a-zl coqueluche/11-coqueluche/13590-acoes-coqueluche 
13. Brazil. Ministry of health. Status of prevention and control of communicable diseases in Brazil. [Accessed: 06/13/2013] http://portal.saude.gov.br/portal/saude/visualizar texto. cfm?idtxt=21901

14. Angela FC, Okano VP, Julio CR. Pertussis booster vaccine for adolescents and young adults in São Paulo, Brazil. Rev. Public Health [Internet]. 2011 Dec [cited 2016 Sep 28]; 45 (6): 11621171. Available in: http://www.scielo.br/scielo.php?script=sci arttext\&pid=S0034-89102011000600008\&lng=pt.

15. Souza AP, Pereira AG.; Escosteguy CC. Annalise the completeness, consistency and epidemiological indicators of tuberculosis in the HSE. Epidemiological Bulletin. 2009; 38. [online journal]. Available at: http://www.hse.rj.saude.gov.br/ profissional/boletim/bol38/analise.asp Accessed on: July 28, 2016.

16. Freitas AC, Okano V, Pereira JCR. Pertussis booster vaccine for adolescents and young adults in São Paulo, Brazil. Rev. Saúde Pública [Internet]. 2011 Dez [citado 2016 Set 28]; 45(6): 11621171

17. Silva FR. O impacto da coqueluche no estado do Rio de Janeiro. Estudo epidemiológico e percepção da biossegurança. Contribuindo para análise da re-emergência no Brasil. Rio de janeiro, 2013.

18. Hidalgo NTR. Coqueluche: normas e instruções. S. I.: CVE, 2000. $26 \mathrm{p}$.

19. Freitas FR, Martin HS, Keico ACMSS, Arantes BAF, Pacheco MA, Waldman EA. Post-vaccine adverse events against diphtheria, pertussis and tetanus vaccinations and factors associated with severity. Rev. Public Health [Internet]. 2007 Dec [2016 Sep 28 mentioned]; 41 (6): 1032-1041.
20. Delamonica And Minujin, Gulaid J. Monitoring equity in immunization coverage. Bull Word Health Organ. 2005 May; 83 (5): 384-91.

21. Ministério Da Saúde. Fundação Nacional de Saúde (FUNASA) Guia de Vigilância Epidemiológica. 4ª ed., Brasília. 2005.

22. Porto MA, Santos CPGG, Granna MLHM, Miranda PP, Celeste $\mathrm{RL}$. Analysis of socioeconomic disparities in vaccine coverage against diphtheria, tetanus and pertussis (DTP)/tetravalent for children under 1 year old in Rio Grande do Sul, 2000-2009. epidemiool. Serv. Health, Brasília, 22 (4): 579-586, outDecember 2013
Publish in International Archives of Medicine

International Archives of Medicine is an open access journal publishing articles encompassing all aspects of medical science and clinical practice. IAM is considered a megajournal with independent sections on all areas of medicine. IAM is a really international journal with authors and board members from all around the world. The journal is widely indexed and classified Q2 in category Medicine. 